\title{
Computer Vision Syndrome and Musculoskeletal Disorders among call center workers of a private company
}

\author{
Mohammed S. Gabal, Khaled M. Abd Elaziz, Nayera S.Mostafa, \\ and Tsneem A. Almadani.
}

Department of community, environmental and occupational medicine, Faculty of Medicine, Ain Shams University

\begin{abstract}
Objectives: to determine the self-reported computer vision syndrome (CVS) and musculoskeletal disorders (MSD) symptoms among a call center workers and to identify the relation between their occurrence and adherence to ergonomics in the call center settings. Research design and methods: an observational cross-sectional study was conducted on 202 workers in a private company call center in Abbasia Egypt; A self-administrated questionnaire including questions about: workers' sociodemographic data, Occupational data, the call center working environment (lighting, temperature ...etc.), used devices (monitor, keyboard...etc.) and workers selfreported computer vision syndrome and musculoskeletal symptoms. In addition, OSHA computer workstation evaluation checklist was used Results: forty eight percent of the workers have musculoskeletal pain since they started working in the center. Neck pain (53\%) and low back pain (52.5\%) were the most reported musculoskeletal symptom. Eye strain $(72.4 \%)$ and headache $(64.4 \%)$ were the commonest reported computer vision syndrome symptoms . The ergonomic evaluation revealed a problem in the working posture in $(87.6 \%)$, a problem in $(98.5 \%)$ related to the seating, $(81.7 \%)$ related to the keyboard and the input device usage and an ergonomic problem in monitors in $(68.8 \%)$ of the workers. Conclusion: Low back pain and neck pain were the highest reported musculoskeletal complains. Headache and eye strain were the highest reported computer vision syndrome symptoms. Although there were ergonomic defects in the work station setting, they were not the significant cause behind workers' symptoms of MSD or CVS.
\end{abstract}

Key words: call center, ergonomics, musculoskeletal disorders, computer vision syndrome

\section{Entroduction}

Call centers (CCs) are a rapidly growing industry, e.g. in South East Asia and India, the annual growth of CCs is $50 \%$ and approximately $37 \%$ of all new jobs within Europe have been in CCs ${ }^{(\mathbf{1})}$. Call center - is a work environment in which the main business is conducted via the telephone whilst simultaneously using display screen equipment (2). The work at Call Center includes not only attending telephone calls, but also includes handling various types of interactions. Thus, the functions of Call Center work include: Work Force Management, Technology Management, Financial Management, Quality Management and Reporting and Communications ${ }^{(3)}$. Call center workers are at risk of developing many work related illnesses such as computer vision syndrome (CVS) and musculoskeletal disorders (MSD). 
Several studies have shown that long periods of constrained sitting or computer work are associated with musculoskeletal symptoms (1). Musculoskeletal disorders (MSDs) are injuries or disorders of the nerves, tendons, muscles and supporting structures of the upper and lower limbs, neck, and lower back that are caused, precipitated or exacerbated by sudden exertion or prolonged exposure to physical factors such as repetition, force, vibration, or awkward posture ${ }^{(4)}$.

Computer vision syndrome (CVS) is characterized by a complex group of eye and vision-related problems that result from prolonged computer use (5). It occurs because the eye and brain react differently to characters on the screen than they do with printed characters; it is difficult for eyes to remain focused, having to continuously refocusing on digital text fatigues the eyes and can lead to burning or tired eyes ${ }^{(6)}$. Most CVSrelated problems can be avoided by appropriate preventive measures, but the majority of computer users are not aware of CVS-related symptoms while some choose to ignore them. ${ }^{(7)}$

\section{Aim of the work}

To determine the frequency of selfreported computer vision syndrome and musculoskeletal disorders symptoms among the workers and to identify the relation between adherence to ergonomics in the call center settings and computer vision syndrome, musculoskeletal disorders occurrence.

\section{Subjects and methods}

Study design:

Observational, cross-sectional study.

\section{Study setting and population:}

The study was conducted in a private company call center in Abbasia district-Egypt.

A sample of 196 was calculated using prevalence of reported musculoskeletal disorders among data processing workers ${ }^{(8)}$, equals to $85 \% \pm 5 \%$ and confidence interval $=$ $95 \%$. The sample was calculated using Epi Info 2002 program. Since the total number of workers in the mentioned setting is 202 , they were all involved in the study.

\section{Study tools}

Data for this study was collected through two tools, the first one was OSHA work station evaluation checklist ${ }^{(9)}$; which comprises seven sections: 1.Working posture, 2.Seating, 3.Keyboard / input device, 4.Monitor, 5.Working area, 6.Accessories, 7.General section including: adjustability of the work station equipment's and their maintenance, in addition to work variability.

The other tool was a selfadministered questionnaire designed by the researcher, using some selected questions from questionnaires of many previous theses. Some questions were also added by the researcher. The questionnaire included questions about: Socio-demographic data (age, gender, and education level), Occupational data (duration of employment, weekly work hours, job description...), Satisfaction about the working environment (lighting, temperature ...etc.) and used devices (monitor, keyboard...etc.), and the self-reported symptoms of computer vision syndrome and musculoskeletal disorders.

\section{Methodology}

Each worker ergonomic relationship to the work station was evaluated 
once, using OSHA evaluation checklist. Any no answer in the seven sections of the checklist means there is an ergonomic defect on that section need to be corrected. Then the questionnaires were answered by the workers.

\section{Statistical methods:}

Data was collected, revised, coded and entered on a personnel computer on excel spreadsheet. Data analysis was done using SPSS (Statistical Package for Social Science) program version 18.

The quantitative data e.g. age were presented as minimum, maximum, mean and standard deviation. Qualitative data e.g. gender, were presented as frequency and percentage. Chi-Square test was used to compare qualitative data between different groups, $\mathrm{P}$ value $<0.05$ was considered statistically significant.

Satisfaction degrees were enumerated from 1 "for very unsatisfied" to 5 "for very satisfied", with the highest level expected to be 60 and the lowest 12.

\section{Ethical consideration:}

The study was approved by the research ethical committee at faculty of medicine Ain Shams University. An approval from the private company administration was taken. All workers were informed about the research and the researcher through an e-mail from the call center manager; in addition a verbal consent was obtained from each worker individually by the researcher prior to giving them the questionnaire.

\section{Results}

This study included 202 workers, $61.9 \%$ were males. The mean age of the workers was $24.91 \pm 2.15$ years; all of them were university graduates. All workers have one hour break per day, $70.3 \%$ of the workers took the break after working for three hours or less (Table1).

Job tasks were different from one job category to another and from day to day, the mean number of calls per day was $80.19 \pm 47.79$. The mean of the daily computer usage hours was $10.02 \pm 2.45$ including inside and outside work usage (Table 2).

Fifty five percent of the workers have heard about ergonomic use of computer. $63.1 \%$ get their information from the media, $20.7 \%$ from a training course at work. Sixty four point nine percent applied the information they have while working on computer (Table 3).

Workers were generally satisfied toward call center environment and equipments with an exception to the noise level in the working hall where $46.5 \%$ of the participants were unsatisfied, and $25.2 \%$ of them were unsatisfied about the chairs (Table 4). Eye strain was the commonest computer vision syndrome symptom, it was reported by $72.8 \%$ of the workers, followed by headache $(64.4$ $\%$ ), blurred vision (35.1\%) and eye dryness or increased tearing $(29.7 \%)$ .Neck pain $53 \%$ and low back pain $52.5 \%$ were the highest musculoskeletal complain during the last month (Table 5).

The ergonomic evaluation of the workers showed that the highest problem in the working posture was the wrist and hand alignment, they were bent up/down or sideway in $69.4 \%$ of the workers.

Seating ergonomic evaluation showed lack of workers lower back support by the chair backrest in $97 \%$ of the workers (Table 6).

Almost eighty three percent of the workers were resting their wrist and 
hand on the hard edge of the desk while using the keyboard and/or the mouse .In $59.9 \%$ of the workers the monitor top was higher than the eyelevel (Table 7).

In the current study participants, wrong ergonomic use of monitors has no statistically significant effect on the development of CVS symptoms (Table 8), and so was the wrong working posture and seating on the development of MSD symptoms (Table 9).

\section{Discussion}

Almost $71 \%$ of the participants have temporary jobs "not showed in tables". This could be explained by the fact that call center business is known for its high turnover rates. The typical call center reports a total turnover rate of $20 \%$ per year ${ }^{(10)}$.

All workers have one hour break in the day. As the break time is flexible, $(70.3 \%)$ of the participant used to take the break after working for three hours or less. Short, frequent breaks are more satisfactory than occasional, longer breaks: e.g., a 5-10 minute break after 50-60 minutes continuous screen and/or keyboard work ${ }^{(11)}$.

The physical environment is an important tool that can be used to improve employee well-being ${ }^{(12)}$. In the current study, $46.3 \%$ of the participants were unsatisfied about noise level, which is in agreement with the results reported by Gavhed and Toomingas, (2006) in a sample of call centers in Sweden, where the ambient sound level at the workstation was considered to be unsatisfactory by $43 \%$ of the operators ${ }^{(13)}$.

Also, $7.4 \%$ of the current study participant were unsatisfied about working hall illumination, $(5.5 \%)$ about illumination at their working desk, and $(7.9 \%)$ were unsatisfied about the monitors they used, which is also less than the results reported by Gavhed and Toomingas, (2006) where $(13 \%)$ of the operators were dissatisfied with the illumination of the room and $(16 \%)$ with that of their desk and $(11 \%)$ were dissatisfied with their visual display units and their placement.

Since workers' sitting to work stations was according to the hot desk method; i.e. the worker sits in the available work station. It is important that furniture and equipment can be adjusted to each individual needs, and also that the operator has the appropriate knowledge about how to adjust and use the equipment in an optimal way. Fifty five percent of the workers have heard about the optimum way of sitting and using computer correctly, of them $(64.9 \%)$ applied their information while working on the computer. This was in alignment with Rakhshaan .et al, (2012) study in Pakistan where 52\% said they had heard about the ergonomics of computer use ${ }^{(14)}$.

More than half get their information mainly from media $(63.1 \%)$, while training course at work was the answer for only (20.7\%). This indicates a serious defect in the training program of the study setting. Office ergonomics training helps employees to understand proper workstation set-up and correct postures (15). Providing highly adjustable chairs without ergonomics training will not reduce the incidence of visual symptoms, workers who received a highly adjustable chair and office ergonomics training had reduced visual symptoms and the effect was maintained through twelve months post-intervention ${ }^{(16)}$. 
The mean computer usage hours for the current study participants was (10.02 \pm 2.45$)$ hours, this could lead to the development of MSD as it was documented by Blatter and Bongers, 2002 that working with a computer for more than 6 hours per day was associated with musculoskeletal symptoms in all body regions ${ }^{(17)}$.

Musculoskeletal and computer vision syndrome symptoms reported in this study were based on the self-reported complaints of the participating workers.

The results of the current study showed that neck, and lower back were the commonest body parts reported by workers to have some sort of aches or pain in the last month, followed by upper back and right shoulder. These results were in agreement with Alazawi, (2007) study results in Baquba -Iraq. He reported that neck, low back and shoulder were the most reported painful body parts ${ }^{(18)}$.

The prevalence of neck pain $(53 \%)$ and low back pain ( 52.5\%) in the current study was in agreement with previous studies results, where the prevalence rate for neck ranged from 27-63\% ( Ortiz-Hernádez et.al, $2003)^{(19)}$ and the rates for the lower back were ranged from $7.4-57.6 \%$ (Juul-Kristensen et.al, 2004) $^{(20)}$.

On the other hand, they were higher than those reported by subbarayalu, (2013) in India (21). He found that Low back Pain is the most prominent work-related musculoskeletal health problem which was reported by $(40 \%)$ of the workers. Neck pain (24\%) was the next most frequently reported musculoskeletal health Problem.

Computer Vision Syndrome is the other health issue covered by this study, It is a widely spread health problem among computer users. The prevalence of CVS in the current study $(72,3 \%)$, was in agreement with the worldwide prevalence of about $(70 \%)^{(22)}$.but higher than that reported by Eduardo Costa et al, (2012), in Brazilian call centers, where it was $(54.6 \%)^{(23)}$.

Eye strain $(72.8 \%)$ was the most experienced symptoms in the current study, followed by headache $(64.4 \%)$, blurred vision $(35.1 \%)$ and eye dryness or increased tearing $(29.7 \%)$. These results were lower than Bali et al, (2007) results, where they reported eye strain in $(97.8 \%)$ of the study subjects, headache in $(82.1 \%)$ and increase tear production in $(66.1 \%)^{(5)}$.

The American Optometric Association (AOA) recommends an eye examination for employees working in occupations that are "highly demanding visually or eye hazardous" every 1 to 2 years for those 18-60 years of age on the basis of an optometrist's professional judgment ${ }^{(24)}$.

The ergonomic evaluation of the study participant and the workstation shows that the workstations design was generally the same across the center. They were not adjustable with no accessories.

An ergonomics defect in the wrist and hand alignment was found in $(69.8 \%)$ of the workers. They were either bent their wrist up/down or sideway toward the little finger.

The chair's evaluation revealed a lack of support to the lower back in (97\%) of the participant; this is because the chair backrest design does not have lumbar curvature and is not adjustable. Adjustability is a very important component in chairs 
ergonomic design, especially if the workers siting to the station is according to the hot desk method. Workers' evaluation while using the keyboard and mouse shows that $(82.7 \%)$ of the workers were resting their wrists and hands on the sharp edge of the desk. Repeated or continuous contact with hard surfaces" contact stress" can create pressure that can inhibit nerve function and blood flow. ${ }^{(25)}$

It was concluded from monitors' evaluation that the level of the screen top in relation to the eye level was inappropriate. It was higher than the eye level in about (60\%) of the participants. They should be placed below eye height to reduce neck muscle activity and take advantage of the natural downward gaze ${ }^{(26)}$.

The OSHA recommends that the top of the monitor should be at or slightly below eye level. The center of the computer monitor should normally be located 15 to 20 degrees below horizontal eye level ${ }^{(9)}$.

This study showed no statistically significant influence of ergonomics defects in the development of musculoskeletal or computer vision syndrome symptoms.

This is explained by the fact that the etiology of musculoskeletal disorders in computer users is multi-factorial including, in addition to the ergonomic factors, the psychological and social factors, such as time pressure and high-perceived workload, which believed to interact in the development of these symptoms ${ }^{(27)}$. Computer vision syndrome symptoms are caused in addition to the ergonomics etiology by ocular etiologies "ocular-surface abnormalities or accommodative spasms"(22). These additional factors were not covered by the current study.

\section{Conclusion and recommendations}

Low back pain and neck pain were the highest reported musculoskeletal complains. Headache and eye strain were the highest CVS symptoms reported by participants, although there were ergonomic problems in the workers relation to the work station but they were not the significant cause behind workers development of MSD and CVS symptoms. So, more extended study is needed to cover all contributing factors. An ergonomic training program is recommended as part of workers training program. A monthly call center clinic report will help to identify the health problems earlier and a pre-employment and periodic eye examination is recommended for $\mathrm{CC}$ workers.

To avoid the complication of the hot disk sitting method, ergonomically designed chairs are recommended.

\section{References}

1) Kerstin Norman, (2005) - Call center work-characteristics, physical, and psychosocial exposure, and health related outcomes, Doctoral Thesis No. 2005-975 issn0345-7524. Retrieved from: http://www.divaportal.org/smash/get/diva2:20713/ful ltext01.

\section{2) Health and Safety Executive,} (2001) - Advice regarding call center working practices, Retrieved from:http://www.ispesl.it/dsl/dsl_rep ository/sch41pdf08marzo06/sche41h se-hela_lac94-1.pdf.

\section{3) North American Quit line Consortium, (2010)-Call Center metrics: Best Practices in Performance measurement and}


Management to maximize Quit line Efficiency and Quality. Retrieved from:

http://c.ymcdn.com/sites/www.naq uitline.org/resource/resmgr/confere nce_call_materials/copy_of_naqc_i ssue_paper_dra.pdf.

\section{4)Centers for Disease Control and} Prevention, (2014) .retrieved March 25, 2014 from: and Thakur, BR., (2007) - Computer vision syndrome: A study of the knowledge, attitudes and practices in Indian Ophthalmologists. Indian journal of ophthalmology, 55 (4): 289-293.

http://wwwn.cdc.gov/nioshsurvapps/gateway/Default.aspx?c=MS Dands=WRT . Bali, J., Navin, N.,

\section{5) Akinbinu, T. R., and Mashalla,} Y.J. (2013) - Knowledge of Computer Vision Syndrome among computer users in the workplace in Abuja, Nigeria. Journal of physiology and pathophysiology,4(4):58-63.

\section{6) Divjak Matjaž, and Bischof} Horst, (2009) - Eye blink-based fatigue detection for prevention of computer vision syndrome .IAPR Conference on Machine Vision applications, Keio University, Hiyoshi, and Japan. Retrieved from: http://www.icg.tugraz.at/Members/ divjak/prework/MVA_2009_paper \%20-\%20Divjak.pdf.

\section{7) Valerie Woods, (2005)-}

Musculoskeletal disorders and visual strain in intensive data processing workers. Occupational Medicine, 55 (2): 121-127.

8)OSHA, (2015) -computer workstation-etools. Retrieved on August 26, 2015, from:
https://www.osha.gov/SLTC/etools/c omputerworkstations/checklist.html.

9) The global call center network, (2007) - The Global Call Center Report: International Perspectives on Management and Employment. Retrieved from: http://digitalcommons.ilr.cornell.edu/ cgi/viewcontent.cgi?article $=1012 \& c$ ontext=reports.

10) Health and Safety Executive, (2002) - Work with display screen equipment. Retrieved from: www.hsebooks.co.uk.

11) Huang, Y.H., Robertson, M.M., and Chang, K., (2004)-The Role of Environmental Control on Environmental Satisfaction, Communication, and Psychological Stress: Effects of Office Ergonomics Training. Environment and Behavior,36(5):617-637.

12) Gavhed,D., and Toomingas,A.,(2006)-Observed physical working conditions in a sample of call centers in Sweden and their relations to directives, recommendations and operators' comfort and symptoms. International Journal of Industrial Ergonomics,37:790-800.

\section{3) Rakhshaan Khan, Rehana} Rehman, Ambreen Surti, and Umar Ali, (2012) - Knowledge and practices of ergonomics in computer users, Journal of the Pakistan Medical Association,62(3):213-217.

14) Ketola, R., Toivonen, R., Hakkanen, M., Luukkonen, R., Takala, E., Viikari-Juntura, E. (2002) -Effects of ergonomic intervention in work with video display units. Scand. J. Work 
Environ. Health 28 (1):18-24.

15) Benjamin C. Amick, Cammie Chaumont Menéndeza,c , Lianna Bazzanid , Michelle Robertsone , Kelly DeRangof, Ted Rooneyd, and Anne Mooreg.(2011) -A field intervention examining the impact of an office ergonomics training and a highly adjustable chair on visual symptoms in a public sector organization . Applied Ergonomics,43:625-631.

16) Blatter, B., and Bongers, P., (2002)-Duration of computer use and mouse use in relation to musculoskeletal disorders of neck and upper limb. International Journal of Industrial Ergonomics,30(4):295306.

17) Alazawi.A, (2007) - Prevalence of musculoskeletal symptoms among Visual Display Terminal users. Tikrit Medical Journal,18(1):127-132.

18) Ortiz-Hernandez, L., TamezGonzalez, S., Martinez-Alcantara, S., and Mendez-Ramirez, I., (2003)

- Computer use increases the risk of musculoskeletal disorders among newspaper office workers. Arch Med Res,

34:331-342.

19) Juul-Kristensen, B., Sogäärd, K., Stroyer, J., and Jensen, C. (2004)-Computer users' risk factors for developing shoulder, elbow and back symptoms. Scand J Work Environ Health, 30:390-398.

20) Subbarayalu Arun Vijay, (2013)-Occupational health problems of call center workers in India: A cross sectional study focusing on gender differences. Journal of Management Science and Practice,
$1(2): 63-70$.

21) Blehm, C., Vishnu, S., Khattak, A., Mitra, S., and Yee, RW. , (2005) - Computer vision syndrome: a review. Survey of Ophthalmology, 50(3): 253-262.

22) Eduardo Costa SA, Mario Ferreira Junior, and Lys Esther Rocha, (2012) - Risk factors for computer visual syndrome (CVS) among operators of two call centers in São Paulo, Brazil. Work,41(1):3568-3574.

23) American

Optometric Association, (2005) - Optometric clinical practice guideline comprehensive adult eye and vision examination. Retrieved from: http://www.aoa.org/documents/CPG1.pdf.

24) Federal Administration, (2009) Workstation and workplace ergonomics at Federal Aviation Administration Operations Control Centers: Phase 1- Evaluation of Ergonomic Issues, Technical Report. Retrieved from: http://hf.tc.faa.gov/technotes/dot-faatc-09-02.pdf.

25) Seghers, J., Jochem, A., and Spaepen, A., (2003) - Posture, muscle activity and muscle fatigue in prolonged VDT work at different screen height settings'. Ergonomics,46(7):714-730.

26) Wahlström Jens, (2005)Ergonomics, Musculoskeletal Disorders and Computer Work. Occupational Medicine 55 (3): 168176. 
Table 1: Workers' distribution according to age, sex and break timing

\begin{tabular}{|c|c|c|c|c|}
\hline & Minimum & Maximum & \multicolumn{2}{|c|}{ Mean \pm SD } \\
\hline Age & 21.00 & 31.00 & \multicolumn{2}{|c|}{$24.91 \pm 2.15$} \\
\hline \multicolumn{3}{|l|}{$\mathrm{N}=202$} & No. & $\%$ \\
\hline \multirow{2}{*}{ Sex } & \multicolumn{2}{|c|}{ Male } & 125 & 61.9 \\
\hline & \multicolumn{2}{|c|}{ Female } & 77 & 38.1 \\
\hline \multirow{2}{*}{$\begin{array}{c}\text { The duration before taking } \\
\text { a break }\end{array}$} & \multicolumn{2}{|c|}{$\leq 3$ hours } & 142 & 70.3 \\
\hline & \multicolumn{2}{|c|}{$>3$ hours } & 60 & 29.7 \\
\hline
\end{tabular}

Table 2: Description of the workers daily working tasks and computer usage

\begin{tabular}{|c|c|c|c|}
\hline Task & Minimum & Maximum & Mean \pm SD \\
\hline $\begin{array}{c}\text { Calling or receiving incoming calls (in } \\
\text { hours) }\end{array}$ & 0.50 & 8.00 & $6.48 \pm 1.37$ \\
\hline $\begin{array}{l}\text { Number of incoming or outgoing } \\
\text { customers' calls / day }\end{array}$ & 0 & 180.00 & $80.19 \pm 47.79$ \\
\hline Call duration ( in seconds ) & 60.00 & 900.00 & $219.67 \pm 86.35$ \\
\hline $\begin{array}{c}\text { Meetings and managerial work (in } \\
\text { hours) }\end{array}$ & 1.00 & 7.00 & $2.82 \pm 1.97$ \\
\hline Only data entry (in hours) & 1.00 & 9.00 & $4.49 \pm 2.42$ \\
\hline $\begin{array}{c}\text { The duration of work before taking a } \\
\text { break (in hours) }\end{array}$ & 0.50 & 7.00 & $2.75 \pm 0.95$ \\
\hline Computer usage/day ( in hours) & 5.00 & 18.00 & $10.02 \pm 2.45$ \\
\hline
\end{tabular}


Table 3: Workers distribution according to previous information about computer safe usage.

\begin{tabular}{|c|c|c|}
\hline & & No. $(\%)$ \\
\hline \multirow{2}{*}{ Participant with previous information $\mathrm{N}=\mathbf{2 0 2}$} & yes & $111(55.0)$ \\
\hline & No & $91(45.0)$ \\
\hline \multicolumn{3}{|l|}{ Information source: } \\
\hline \multirow{2}{*}{ Training course at work } & yes & $23(20.7)$ \\
\hline & No & $88(79.3)$ \\
\hline \multirow{2}{*}{ Media } & yes & $70(63.1)$ \\
\hline & No & $41(36.9)$ \\
\hline \multirow{2}{*}{ Friends and relatives } & yes & $37(33.3)$ \\
\hline & No & $74(66.7)$ \\
\hline \multirow{5}{*}{ Others } & $\begin{array}{l}\text { Educational } \\
\text { curriculum }\end{array}$ & $9(8.1)$ \\
\hline & Books & $3(2.7)$ \\
\hline & Course outside work & $3(2.7)$ \\
\hline & Doctor & $1(0.9)$ \\
\hline & No & $95(85.6)$ \\
\hline \multirow{2}{*}{ Applied the information while working } & yes & $72(64.9)$ \\
\hline & No & $39(35.1)$ \\
\hline
\end{tabular}


Table 4: Workers' satisfaction toward current work environment

\begin{tabular}{|c|c|c|c|c|c|}
\hline \multirow{2}{*}{$\begin{array}{c}\text { Work } \\
\text { environment } \\
\text { items }\end{array}$} & \multicolumn{5}{|c|}{$\begin{array}{c}\text { Satisfaction level } \\
\text { No. }(\%)\end{array}$} \\
\hline & $\begin{array}{c}\text { Very } \\
\text { satisfied }\end{array}$ & Satisfied & Neutral & unsatisfied & $\begin{array}{c}\text { Very } \\
\text { unsatisfied }\end{array}$ \\
\hline $\begin{array}{l}\text { General lighting } \\
\text { in the hall }\end{array}$ & 78 (38.6) & $\begin{array}{c}102 \\
(50.5)\end{array}$ & $7(3.5)$ & $15(7.4)$ & $0(0.0)$ \\
\hline $\begin{array}{c}\text { Lighting at the } \\
\text { desk }\end{array}$ & $71(35.1)$ & $\begin{array}{c}96 \\
(47.5)\end{array}$ & $\begin{array}{c}24 \\
(11.9)\end{array}$ & $9(4.5)$ & $2(1.0)$ \\
\hline Temperature & $49(24.3)$ & $\begin{array}{c}104 \\
(51.4)\end{array}$ & $\begin{array}{c}27 \\
(13.4)\end{array}$ & $18(8.9)$ & $4(2.0)$ \\
\hline Noise & $9(4.5)$ & $64(31.7)$ & $\begin{array}{c}35 \\
(17.3)\end{array}$ & $67(33.1)$ & $27(13.4)$ \\
\hline $\begin{array}{l}\text { Working station } \\
\text { space }\end{array}$ & $33(16.3)$ & $\begin{array}{c}112 \\
(55.4)\end{array}$ & $\begin{array}{c}35 \\
(17.3)\end{array}$ & $20(10.0)$ & $2(1.0)$ \\
\hline Desk & $30(14.9)$ & $\begin{array}{c}134 \\
(66.2)\end{array}$ & $\begin{array}{c}25 \\
(12.4)\end{array}$ & $10(5.0)$ & $3(1.5)$ \\
\hline Chair & $23(11.4)$ & $98(48.5)$ & $\begin{array}{c}30 \\
(14.9)\end{array}$ & $34(16.8)$ & $17(8.4)$ \\
\hline Monitor & $42(20.8)$ & $\begin{array}{c}122 \\
(60.4)\end{array}$ & $\begin{array}{c}22 \\
(10.9)\end{array}$ & $13(6.4)$ & $3(1.5)$ \\
\hline Keyboard & $51(25.2)$ & $\begin{array}{c}122 \\
(60.4)\end{array}$ & $18(8.9)$ & $10(5.0)$ & $1(0.5)$ \\
\hline Mouse & $46(22.8)$ & $\begin{array}{c}121 \\
(59.9)\end{array}$ & $18(8.9)$ & $14(6.9)$ & $3(1.5)$ \\
\hline Headset & $33(16.3)$ & $99(49.0)$ & $\begin{array}{c}36 \\
(17.8)\end{array}$ & $22(10.9)$ & $12(6)$ \\
\hline $\begin{array}{c}\text { Headset sound } \\
\text { level }\end{array}$ & $26(12.9)$ & $94(46.5)$ & $\begin{array}{c}37 \\
(18.3)\end{array}$ & $31(15.3)$ & $14(7)$ \\
\hline
\end{tabular}


Table 5: Frequency of Computer Vision Syndrome, and musculoskeletal symptoms reported by participants in the last month

\begin{tabular}{|c|c|c|}
\hline \multirow{2}{*}{ CVS Symptom } & \multicolumn{2}{|c|}{$\begin{array}{l}\text { Occurrence of symptoms in the last month } \\
\qquad N=202\end{array}$} \\
\hline & $\begin{array}{c}\text { YES } \\
\text { No. }(\%) \\
\end{array}$ & $\begin{array}{c}\text { NO } \\
\text { No. }(\%) \\
\end{array}$ \\
\hline Headache & 130 & $72 \quad(35.6)$ \\
\hline Eye strain & $147 \quad(72.8)$ & $55 \quad(27.2)$ \\
\hline Eye dryness or an increase in tears & $60 \quad(29.7)$ & $142(70.3)$ \\
\hline Blurred vision & $71 \quad(35.1)$ & 131 \\
\hline \multicolumn{3}{|l|}{ Musculoskeletal pain / discomfort } \\
\hline Neck & $107(53.0)$ & $95(47.0)$ \\
\hline Right shoulder & $45(22.3)$ & $157(77.7)$ \\
\hline Left shoulder & $33(16.3)$ & $169(83.7)$ \\
\hline Right upper arm & $37(18.3)$ & $165(81.7)$ \\
\hline Left upper arm & $21(10.4)$ & $181(89.6)$ \\
\hline Right forearm & $35(17.3)$ & $167(82.7)$ \\
\hline Left forearm & $23(11.4)$ & $179(88.6)$ \\
\hline Right wrist & $36(17.9)$ & $166(82.1)$ \\
\hline Left wrist & $18(8.9)$ & $184(91.1)$ \\
\hline Numbness in one or both hands & $44 \quad(21.8)$ & $158(78.2)$ \\
\hline Right hand & $35(17.3)$ & $167(82.7)$ \\
\hline Left hand & $22(10.9)$ & $180(89.1)$ \\
\hline Upper back & $79(39.1)$ & $123(60.9)$ \\
\hline Lower back & $106(52.5)$ & $96(47.5)$ \\
\hline Right thigh & $13(6.4)$ & 189 (93.6) \\
\hline Left thigh & $13(6.4)$ & 189 (93.6) \\
\hline Right leg & $31(15.3)$ & $171(84.7$ \\
\hline Left leg & $33(16.3)$ & $169(83.7)$ \\
\hline Right foot & $37(18.3)$ & $165(81.7)$ \\
\hline Left foot & $34(16.8)$ & $168(83.2)$ \\
\hline
\end{tabular}


Table 6: Working posture and seating ergonomic evaluation

\begin{tabular}{|c|c|c|}
\hline Working posture check list elements' & $\begin{array}{l}\text { YES } \\
\text { No. }(\%)\end{array}$ & $\begin{array}{c}\text { NO } \\
\text { No. }(\%)\end{array}$ \\
\hline Head and neck are upright, or in-line with the torso & $170(84.2)$ & $32(15.8)$ \\
\hline Head, neck, and trunk face forward & $201(99.5)$ & $1(0.5)$ \\
\hline Trunk is perpendicular to floor & $169(83.7)$ & $33(16.3)$ \\
\hline Shoulders and upper arms are in-line with the torso & $198(98.0)$ & $4(2.0)$ \\
\hline Upper arms and elbows are close to the body & $199(98.5)$ & $3(1.5)$ \\
\hline Forearms, wrists, and hands are straight and in-line & $120(59.4)$ & $82(40.6)$ \\
\hline $\begin{array}{c}\text { Wrists and hands are straight (not bent up/down or sideways } \\
\text { toward the little finger) }\end{array}$ & $61(30.2)$ & $141(69.8)$ \\
\hline $\begin{array}{c}\text { Thighs are parallel to the floor and the lower legs are } \\
\text { perpendicular to floor }\end{array}$ & $202(100.0)$ & $0(0.0)$ \\
\hline Feet rest flat on the floor or are supported by a stable footrest & $188(93.1)$ & $14(6.9)$ \\
\hline \multicolumn{3}{|l|}{ Chair check list elements' } \\
\hline Backrest provides support for the lower back & $6 \quad(3.0)$ & $196(97.0)$ \\
\hline Seat width and depth accommodate the specific user & $202(100)$ & $0 \quad(0.0)$ \\
\hline $\begin{array}{c}\text { Seat front does not press against the back of the knees and } \\
\text { lower legs }\end{array}$ & $202(100)$ & $\begin{array}{ll}0 & (0.0)\end{array}$ \\
\hline Seat has cushioning and is rounded with a "waterfall" front & $202(100)$ & $0 \quad(0.0)$ \\
\hline $\begin{array}{c}\text { Armrests, if used, support both forearms while performing } \\
\text { computer tasks } * N=190\end{array}$ & $76(40.0)$ & $114 \quad(60.0)$ \\
\hline
\end{tabular}

* 12 participant were not using the armrest during work 
Table 7: Keyboard/input device and monitors ergonomic evaluation

\begin{tabular}{|c|c|c|}
\hline Keyboard/input device check list elements' & $\begin{array}{l}\text { YES } \\
\text { No. }(\%)\end{array}$ & $\begin{array}{l}\text { NO } \\
\text { No. }(\%)\end{array}$ \\
\hline $\begin{array}{l}\text { Input device (mouse or trackball) is located right next to your } \\
\text { keyboard } * \mathrm{~N}=192\end{array}$ & 191( 99.5) & $1(0.5)$ \\
\hline $\begin{array}{l}\text { Input device is easy to activate and the shape/size fits your hand } \\
\qquad * N=192\end{array}$ & $192(100 \%)$ & $0(0.0)$ \\
\hline $\begin{array}{l}\text { Wrists and hands do not rest on sharp or hard edges } \\
\qquad \mathrm{N}=202\end{array}$ & $35(17.3)$ & $167(82.7)$ \\
\hline \multicolumn{3}{|l|}{ Monitor checklist elements' } \\
\hline Top of the screen is at or below eye level & $81(40.1)$ & $121(59.9)$ \\
\hline $\begin{array}{l}\text { User with bifocals/trifocals can read the screen without bending } \\
\text { the head or neck backward. } * N=32\end{array}$ & $30(96.8)$ & $1(3.2)$ \\
\hline $\begin{array}{c}\text { Monitor distance allows worker to read the screen without } \\
\text { leaning forward or backward }\end{array}$ & $180(89.1)$ & $22(10.9)$ \\
\hline $\begin{array}{l}\text { Monitor position is directly in front of the worker so he/ she don't } \\
\text { have to twist his/her head or neck. }\end{array}$ & $201(99.5)$ & $1(0.5)$ \\
\hline Glare is not reflected on screen. & $186(92.1)$ & $16(7.9)$ \\
\hline
\end{tabular}

* Only 32 participant were using eyeglass during computer usage

Table 8: Effect of wrong monitor usage on development of CVS symptoms

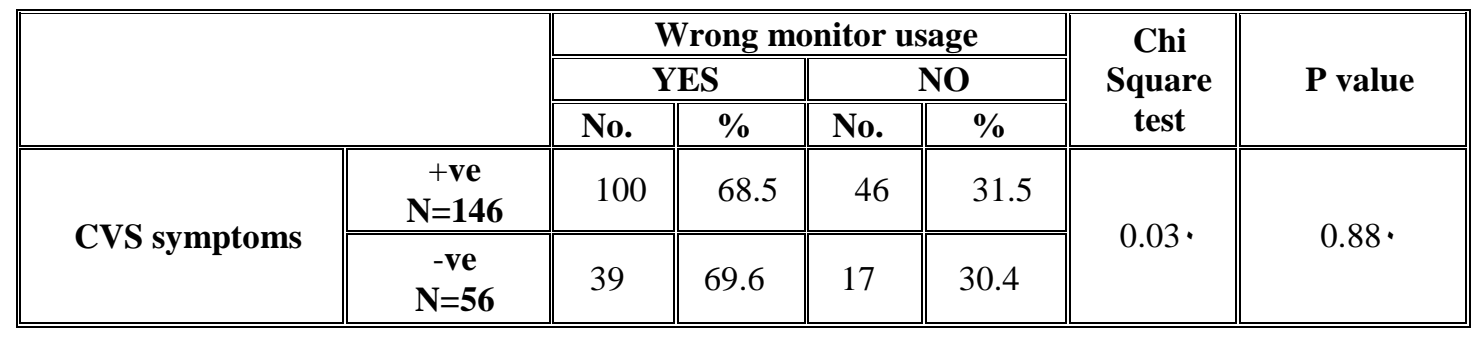

Table 9: Effect of wrong working postures or wrong seating on the presence of muscle or joint pain

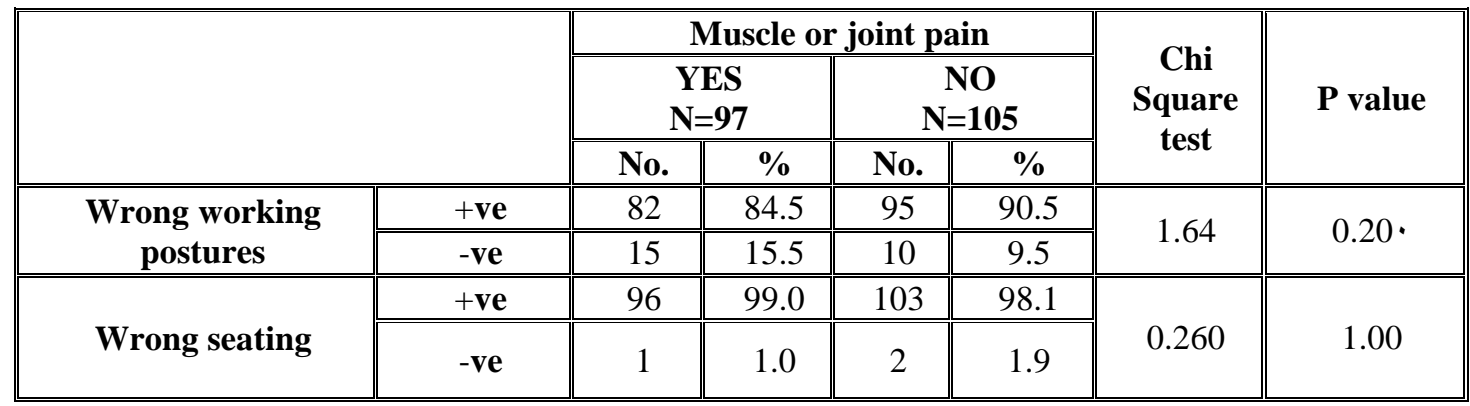

